\title{
The Effect of 24/7, Digital-First, NHS Primary Care on Acute Hospital Spending: Retrospective Observational Analysis
}

Sam Winward, MBChB, BSc; Tejal Patel, MBBS; Mazin Al-Saffar, MBBS, BSc; Matthew Noble, MBBS

Babylon Health, London, United Kingdom

Corresponding Author:

Sam Winward, MBChB, BSc

Babylon Health

1 Knightsbridge Green

London, SW1X 7QA

United Kingdom

Phone: 4403302231008

Email: sam.winward@babylonhealth.com

\section{Abstract}

Background: Digital health has the potential to revolutionize health care by improving accessibility, patient experience, outcomes, productivity, safety, and cost efficiency. In England, the NHS (National Health Service) Long Term Plan promised the right to access digital-first primary care by March 31, 2024. However, there are few global, fully digital-first providers and limited research into their effects on cost from a health system perspective.

Objective: The aim of this study was to evaluate the impact of highly accessible, digital-first primary care on acute hospital spending.

Methods: A retrospective, observational analysis compared acute hospital spending on patients registered to a 24/7, digital-first model of NHS primary care with that on patients registered to all other practices in North West London Collaboration of Clinical Commissioning Groups. Acute hospital spending data per practice were obtained under a freedom of information request. Three versions of NHS techniques designed to fairly allocate funding according to need were used to standardize or "weight" the practice populations; hence, there are 3 results for each year. The weighting adjusted the populations for characteristics that impact health care spending, such as age, sex, and deprivation. The total spending was divided by the number of standardized or weighted patients to give the spending per weighted patient, which was used to compare the 2 groups in the NHS financial years (FY) 2018-2019 (FY18/19) and 2019-2020 (FY19/20). FY18/19 costs were adjusted for inflation, so they were comparable with the values of FY19/20.

Results: The NHS spending on acute hospital care for 2.43 million and 2.54 million people (FY18/19 and FY19/20) across 358 practices and 49 primary care networks was $£ 1.6$ billion and $£ 1.65$ billion (a currency exchange rate of $£ 1=U S \$ 1.38$ is applicable), respectively. The spending on acute care per weighted patient for Babylon GP at Hand members was 12\%, 31\%, and 54\% (£93, $P=.047$; $£ 223, P<.001$; and $£ 389, P<.001)$ lower than the regional average in FY18/19 for the 3 weighting methodologies used. In FY19/20, it was $15 \%, 35 \%$, and 51\% (£114, $P=.006 ; £ 246, P<.001$; and $£ 362, P<.001)$ lower. This amounted to lower costs for the Babylon GP at Hand population of $£ 1.37, £ 4.40$ million, and $£ 11.6$ million, respectively, in FY18/19; and $£ 3.26$ million, $£ 9.54$ million, and $£ 18.8$ million, respectively, in FY19/20.

Conclusions: Patients with access to $24 / 7$, digital-first primary care incurred significantly lower acute hospital costs.

(J Med Internet Res 2021;23(7):e24917) doi: 10.2196/24917

\section{KEYWORDS}

primary health care; family practice; general practice; cost; cost analysis; telemedicine; digital technology; digital health; digital care; virtual care; hospital; retrospective; observational; cohort; finance; economics; health services research

\section{Introduction}

Health systems across the world are experiencing rising health care costs as a percentage of gross domestic product (GDP) [1].
As the global population continues to age [2], this is expected to worsen. Despite the associated increase in health outcomes, technological improvement is considered a further core driver of health care cost growth [3]. Resultantly, health systems rigorously assess the cost-benefit of such technologies before 
implementation. That same rigor has not been consistently applied to digital health solutions; hence, there is increasing concern that their proliferation is outpacing their monitoring and evaluation [4-7].

The COVID-19 pandemic has catalyzed the adoption and growth of digital technologies [8-11], intensifying the need to understand their impact. In particular, the use of telehealth, defined as the "delivery of healthcare services, where patients and providers are separated by distance" [12], has surged. As the world emerges from the pandemic, systems must begin to plan which technologies will form part of the new norm.

The capability of telehealth is well understood in terms of its potential to increase accessibility and patient satisfaction [13-17], increase efficiency [18,19], and improve clinical outcomes [20-22] while remaining safe [16]. The evidence is less clear on its cost-effectiveness. Several large-scale reviews concluded that the majority of interventions are cost-effective [23-25], while others are uncertain [19,26,27], including a Cochrane systematic review that stated the cost-benefit of telemedicine for a health system is unclear [26]. The contrasting nature of findings is in part related to the variety of evaluation methodologies and cost resources assessed; for example, one review stated that the predominant reason for cost savings was reduced travel costs [19]. Generally, telehealth cost-effectiveness studies are limited to a single clinical specialty or service modality but importantly do not consider the perspective of the health system [19]. This can lead to inconclusive assessments; as Rahimi [28] highlights, health systems are often in a state of disequilibrium, and new services can address unmet demand, which can cause net increases in expenditure.

One way to overcome this is to assess "all-cause" health care spending, as two recent digital health studies have done [29,30]. Both studies examined digital care management solutions that leverage proactive approaches and must be patient-focussed to succeed. As a result, they have higher potential to deliver savings to a health care system than do simpler telehealth-as-a-service solutions. Such offerings are most commonly a blend of telehealth, eHealth, and mobile health solutions but generally address a single condition.

This paper considers the management of the entire health care needs of a whole population through the provision of highly accessible, digital-first primary care in the English NHS (National Health Service). The NHS Long Term Plan states that all patients should have the right to choose fully digital-first primary care by March 31, 2024 [31]. Increased accessibility to primary care has been shown to reduce emergency department (ED) attendances [32], but little is known about the overall financial impact this service model will have on the health care system. The aim of this paper was to evaluate the impact that access to 24/7, highly accessible, digital-first primary care has on acute hospital spending.

\section{Methods}

\section{Study Setting}

Babylon GP at Hand is an NHS general practice in England, which is free at the point of need and provides full NHS primary care services under the General Medical Services contract to people living or working in London, Birmingham, and surrounding areas $[33,34]$.

It was the first NHS general practice to adopt a fully digital-first model of primary care and has been operating across London in this way since November 2017. This means a member's first and main point of contact is digital, with either a smartphone app or a web browser being used to access a virtual appointment. In-person services are available when required at 6 sites across London and 1 in Birmingham (2020).

Babylon GP at Hand is accessible for members day and night 365 days a year, with $80 \%$ of all appointments being digital (SG Winward, MD, unpublished data, April 1, 2019, to March $31,2020)$. This is more than 3 times the "core hours" stipulated in the standard primary care contract (8 AM-6:30 PM Monday to Friday) [34]. Appointments are therefore available at a time and place convenient for members, and $40 \%$ of all appointments occur outside the contracted core hours. Access to medical advice and information is fast; $67 \%$ of virtual appointments are available within 2 hours of booking, and $81 \%$ of all appointments (including those in person) occur within 48 hours of booking (SG Winward, MD, unpublished data, April 1, 2019, to March 31, 2020); meanwhile, the national average of appointments occurring the same or next day is $49 \%$ [35]. Members also have access to a comprehensive suite of digital self-care technology, which can check symptoms; perform a digital health assessment; and monitor symptoms, observations, activity, and mood through the Babylon app.

All services are free for registered members, who must live or work within 40 minutes of a Babylon GP at Hand clinic to be eligible. If previously registered with another NHS practice, the members can switch to their registered GP practice to Babylon GP at Hand. The list size has grown from 3000 to over 100,000 members since November 2017, and the Babylon GP at Hand became the largest single practice in the United Kingdom in August 2020 [33].

\section{Data Sources}

The commissioner spending on acute hospital care was compared between patients registered at Babylon GP at Hand and patients registered at other practices in the North West London Collaboration of Clinical Commissioning Groups for the NHS financial years (FYs) of April 1, 2018 to March 31, 2019 (FY18/19); and April 1, 2019, to March 31, 2020 (FY19/20).

Following a freedom of information (FOI) request, the total acute hospital spending for patients registered at each general practice in North West London Collaboration of Clinical Commissioning Groups was received and aggregated at the level of each practice (Multimedia Appendix 1). The data represented all costs incurred for patients registered at practices in the commissioning region at acute providers. This included acute and general hospital care, such as ED, inpatients, critical care, outpatients, and maternity services, including all associated costs, such as laboratory costs. It did not include mental health spending (eg, inpatient mental health admissions), community spending (eg, district nursing), or specialized services (eg, the 
treatment of rare cancers, genetic disorders, or complex medical or surgical conditions), as these services are not consistently provided by all acute trusts or are funded by national rather than local commissioners. Primary care prescription spending was not included in the FOI response, but medications prescribed in hospital were.

Practices were eligible for inclusion if they were active during FY18/19 or FY19/20. Spending was excluded that could not be associated with a patient population.

\section{Weighting the Populations}

Figure 1 shows an overview of the methodology used to compare spending; the total spending per practice is divided by the number of need-adjusted or "weighted" patients. Any differences in the spending per weighted patient between populations would therefore be for reasons other than health care need.

Figure 1. Overview of methodology.

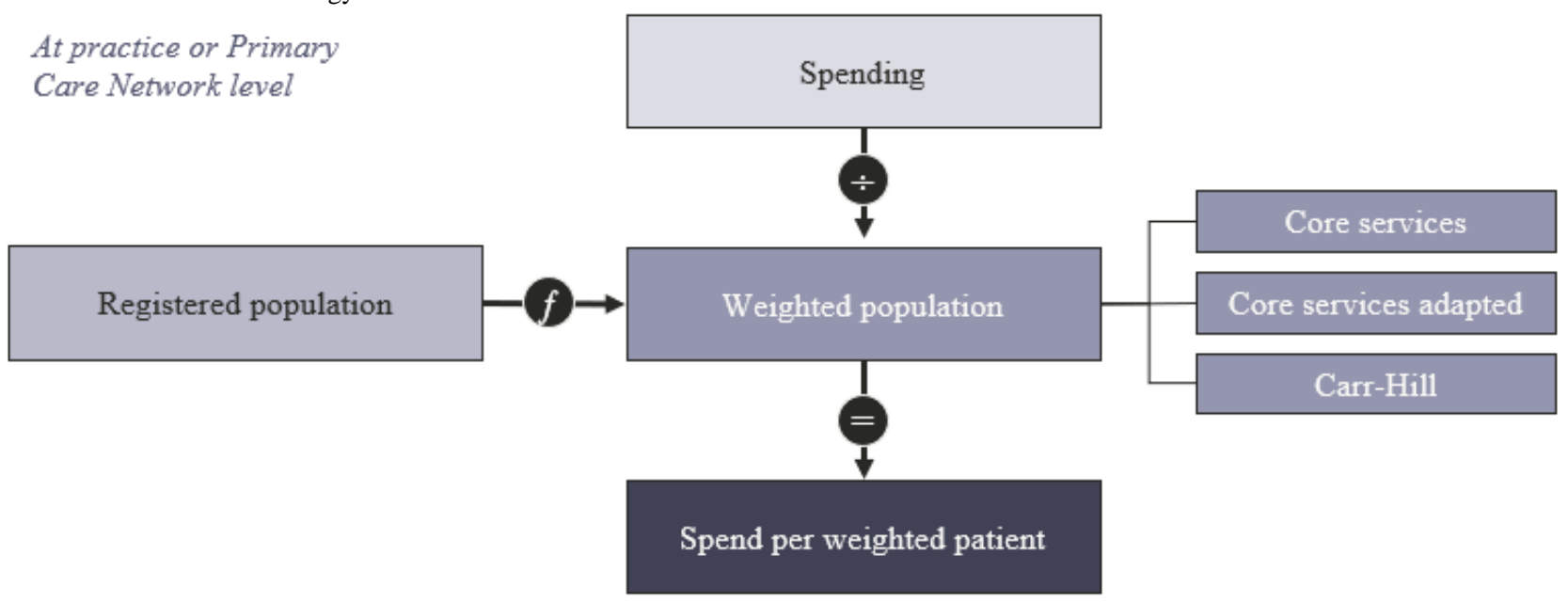

As the populations registered to each practice were not constant throughout the NHS financial year, an average registered population was calculated based on the practice population at the start of each quarter [33]. All further references to a practice's registered population size are based on this averaged value.

The demographics and health needs of different populations can vary greatly, so each population must be adjusted before their spending can be compared. Existing NHS methodologies were replicated to achieve this. They exist to ensure public funding is distributed fairly by adjusting for characteristics known to impact health care spending, such as, age, sex, and deprivation (Table 1). This transformed the registered population for each practice into a weighted population. For example, if a population with certain characteristics was expected to incur twice the costs of another, it would have twice the number of weighted patients than the other.

Three methods were used to weight the populations, resulting in three weighted populations for each practice (Table 1) [36-39].

Table 1. Description of 3 methodologies used to weight patient populations to enable the comparison of spending.

\begin{tabular}{|c|c|}
\hline Weighting & Description \\
\hline Core services [36] & $\begin{array}{l}\text { Around } £ 80 \text { billion of NHS }{ }^{\text {a }} \text { funding per year is distributed to commissioners for "core services". The core services formula is } \\
\text { used to ensure fair distribution of this amount to populations with different characteristics. It has separate components that weight } \\
\text { each practice’s population for their need for services, including general and acute, mental health, maternity, community care, } \\
\text { and prescription needs. In addition, each population is adjusted for local factors: health care utilization, supply of health care } \\
\text { services, pricing, unavoidable costs, unmet need (with premature mortality rate used as a proxy), local deprivation, and costs } \\
\text { due to unavoidable smallness. }\end{array}$ \\
\hline $\begin{array}{l}\text { Core services } \\
\text { adapted }\end{array}$ & $\begin{array}{l}\text { Three adaptations were made to the core services methodology to better match the spending data received in the freedom of in- } \\
\text { formation request. First, as the spending data received did not include mental health, community, or prescription costs, these } \\
\text { elements were removed from the formula. Second, the Babylon GP at Hand population was reweighted by the actual age and } \\
\text { sex characteristics as opposed to the estimates provided in the core services file. As Babylon GP at Hand is a fast-growing } \\
\text { practice, it was over } 3 \text { times the size of the estimation [37]. Third, the core services formula assumes that all Babylon GP at } \\
\text { Hand patients live in Hammersmith and Fulham, whereas the majority live in other clinical commissioning groups. To improve } \\
\text { the accuracy, the local components from each patient's home residence were used. }\end{array}$ \\
\hline
\end{tabular}

${ }^{\mathrm{a}}$ NHS: National Health Service. 


\section{Cost Per Weighted Patient}

The total spending for each practice was divided by its number of weighted patients, giving the spending per weighted patient for that practice. This was also performed at the level of the primary care networks, which are groups of practices that work collaboratively, totalling around 50,000 people each [40,41]. Primary care networks (groupings of general practices) are more similar in size to the Babylon GP at Hand practice than are other practices and hence are a more appropriate grouping to compare against.

\section{Adjustments for the Babylon GP at Hand Practice}

To increase the accuracy of the calculation for Babylon GP at Hand, 3 adjustments were applied.

First, patients registered at Babylon GP at Hand's Birmingham site were removed. As spending data were only received for hospitals in Greater London, no reciprocal adjustments were made to the spending. The Birmingham site opened in June 2019, so this only affected FY19/20.

Second, Babylon GP at Hand launched from an existing practice in July 2017. A cohort of patients who lived near to the Hammersmith and Fulham site continued to receive a traditional model of primary care from the existing provider. This population was removed to better assess the effects of Babylon GP at Hand model of care. As spend data were only received at a practice level, this group of patients was assigned the average weighting and average cost per patient for the Hammersmith and Fulham Clinical Commissioning Group to remove them from the Babylon GP at Hand practice totals.

Third, an independent review of Babylon GP at Hand, commissioned by NHS England, reported that patients who joined the practice were less likely to use certain hospital services in the 12 months prior to joining than were a matched population [42]. If this observation persisted after patient joining, this would imply that the Babylon GP at Hand population would incur lower costs even after adjustment for the characteristics of its populations. To conservatively account for this potential effect, the cost per weighted patient for Babylon GP at Hand was inflated. To determine the degree of inflation, population data, national reference costs, and attendance rates for each age and sex category were used to calculate the expected costs for the Babylon GP at Hand population $[43,44]$. The same calculation was then performed using the attendance rates modified by the findings in the independent review [42]. A $12 \%$ difference between the 2 represented the degree to which the actual cost would be lower than the expected cost, and hence the Babylon GP at Hand spending per weighted patient was increased by this factor.

\section{Adjustment for Inflation}

Costs for FY18/19 were adjusted for inflation to be equivalent to FY19/20 values. The GDP deflator at market prices for the United Kingdom was used as produced by Her Majesty's Treasury and published by the Office of National Statistics [45].

\section{Data Analysis}

Analysis was performed on SciPy package version 1.5.4 (Python) [46]. Shapiro-Wilk and Kolmogorov-Smirnov tests were used to determine if the data were normally distributed before a 1-sided, simple $z$ test was performed to compare the spending per weighted patient between groups.

\section{Results}

Figure 2 follows the methodology outlined in Figure 1 to calculate the cost per weighted patient, with the core services methodology being used in FY19/20, including all adjustments. 
Figure 2. Flow chart demonstrating how the spending per weighted patient for the core services methodology was calculated for the financial year 2019-2020. BGPaH: Babylon GP at Hand practice; NWLCCCG: North West London Collaboration of Clinical Commissioning Groups.

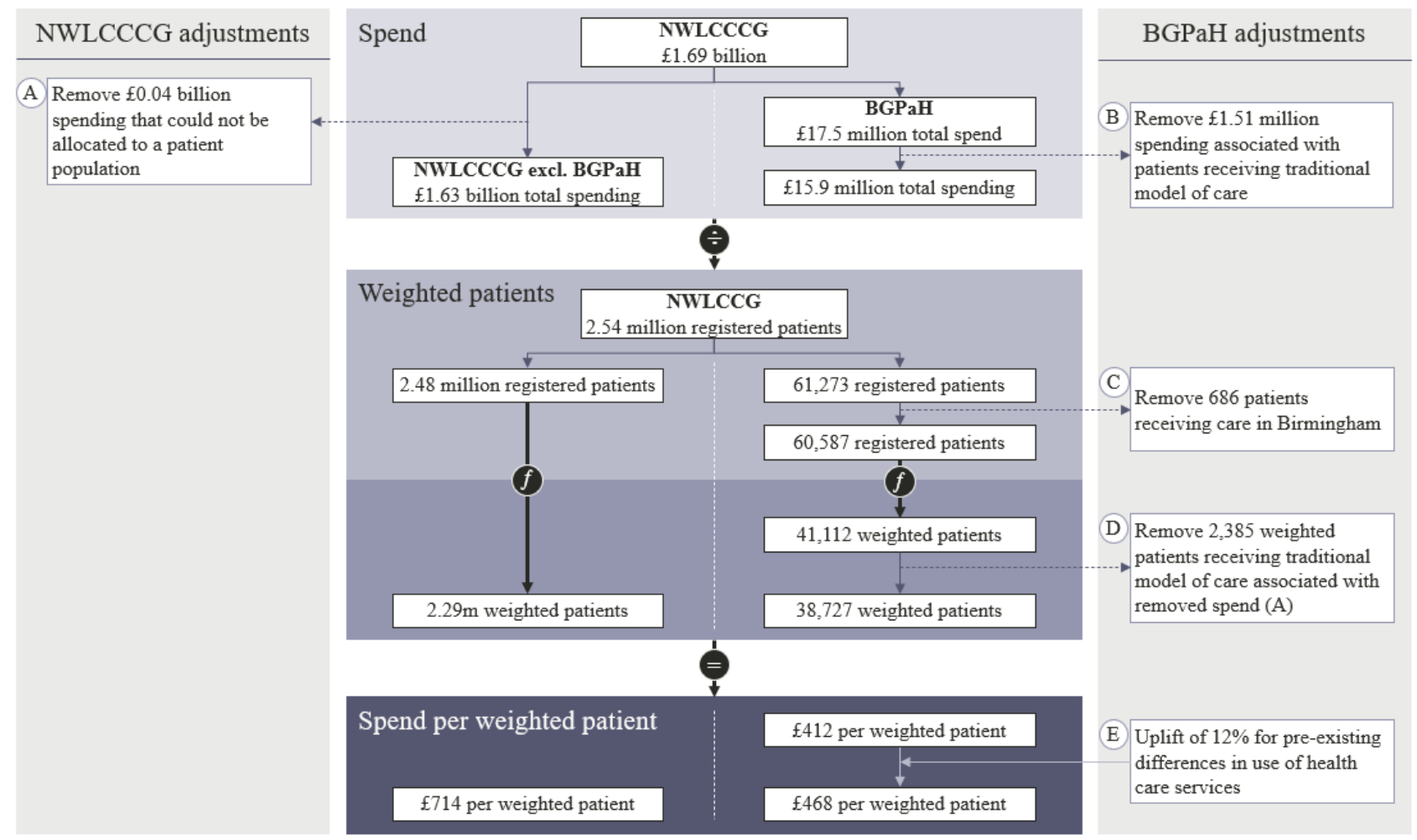

\section{Spending}

The total acute care spending returned in the FOI was $£ 1.64$ billion in FY18/19 and $£ 1.69$ billion in FY19/20 (a currency exchange rate of $£ 1=\mathrm{US} \$ 1.38$ is applicable), across 361 practices. An expenditure of $£ 44.6$ million (2.71\%) in FY18/19 and $£ 43.4$ million $(2.56 \%)$ in FY19/20 was excluded that was associated with 3 practices and an "Unknown Primary Care Network" in the FOI response, as the costs could not be attributed to a patient population (Figure 2A). The remaining spending was $£ 1.6$ billion in FY18/19 and $£ 1.65$ billion in FY19/20 across 358 practices including Babylon GP at Hand.

The spending for Babylon GP at Hand practice was $£ 8.6$ million in FY18/19 and $£ 15.9$ million in FY19/20,after the spending associated with patients receiving a traditional model of care ( 1.59 million and $£ 1.51$ million, respectively) was removed (Figure 2B).

\section{Registered Population}

The 358 practices had a total registered population of 2.43 million patients in FY18/19 and 2.54 million in FY19/20.
The registered population at Babylon GP at Hand was 32,393 and 61,273 patients for FY18/19 and FY19/20, respectively. There was total of 60,587 patients after 686 patients registered to the Birmingham site in FY19/20 were removed (Figure 2C). This population included 2563 and 2696 registered patients in FY18/19 and FY19/20, respectively, who received a traditional model of care. This population and the associated spending was removed (Figure 2D).

The remaining 357 practices in the region had an average of 6718 registered patients (range 235-21,688) in FY18/19 and 6943 (range 224-22,969) in FY19/20. There were 48 primary care networks (excluding the Babylon GP at Hand primary care network) in the North West London region, which had on average 49,682 registered patients (range 28,318-80,903) in FY18/19 and 51,358 (range 29,125-83,965) in FY19/20.

Compared with the North West London Collaboration of Clinical Commissioning Group population, the Babylon GP at Hand population was more concentrated in working age adults, had higher rates of employment, and experienced similar levels of deprivation (Table 2). 
Table 2. Sociodemographic characteristics of the populations $[33,47]$.

\begin{tabular}{|c|c|c|c|c|}
\hline \multirow[t]{2}{*}{ Sociodemographic indicators } & \multicolumn{2}{|l|}{$\mathrm{FY} 18 / 19^{\mathrm{a}}$} & \multicolumn{2}{|l|}{$\mathrm{FY} 19 / 20^{\mathrm{b}}$} \\
\hline & $\mathrm{BGPaH}^{\mathrm{c}}(\mathrm{n}=32,394)$ & $\operatorname{NWLCCCG}^{\mathrm{d}}(\mathrm{n}=2,398,352)$ & BGPaH $(n=60,587)$ & $\operatorname{NWLCCCG~}(\mathrm{n}=2,478,711)$ \\
\hline \multicolumn{5}{|l|}{ Population by age band, $\mathrm{n}(\%)$} \\
\hline Female 0-19 & $729(2.25)$ & $255,803(10.67)$ & $987(1.63)$ & $262,433(10.59)$ \\
\hline Female 20-39 & $12,221(37.73)$ & $425,275(17.73)$ & $24,040(39.68)$ & $437,143(17.64)$ \\
\hline Female 40-59 & $1208(3.73)$ & $294,998(12.3)$ & $1881(3.1)$ & $306,834(12.38)$ \\
\hline Female $60-79$ & $205(0.63)$ & $154,813(6.45)$ & $244(0.4)$ & $160,536(6.48)$ \\
\hline Female $80+$ & $37(0.11)$ & $42,439(1.77)$ & $39(0.06)$ & $43,822(1.77)$ \\
\hline Male 0-19 & $551(1.7)$ & $269,153(11.22)$ & $814(1.34)$ & $275,767(11.13)$ \\
\hline Male 20-39 & $14,474(44.68)$ & 430,981 (17.97) & $27,757(45.81)$ & $442,271(17.84)$ \\
\hline Male 40-59 & $2675(8.26)$ & $348,327(14.52)$ & $4436(7.32)$ & $365,469(14.74)$ \\
\hline Male 60-79 & $268(0.83)$ & $146,604(6.11)$ & $361(0.6)$ & $153,160(6.18)$ \\
\hline Male $80+$ & $26(0.08)$ & $29,959(1.25)$ & $29(0.05)$ & $31,276(1.26)$ \\
\hline Index of multiple deprivation $^{\mathrm{e}}$, percentile ${ }^{\mathrm{f}}$ & $\mathrm{N} / \mathrm{A}^{\mathrm{g}}$ & $\mathrm{N} / \mathrm{A}^{\mathrm{g}}$ & 45 th & $52 \mathrm{nd}$ \\
\hline \multicolumn{5}{|l|}{ Employment status ${ }^{\mathbf{h}}(\%)$} \\
\hline Employed $^{\mathrm{i}}$ & 94.2 & 68.7 & 90.5 & 68.9 \\
\hline Unemployed & 0.1 & 5.3 & 4.0 & 5.3 \\
\hline Other $^{\mathrm{j}}$ & 5.7 & 26.1 & 5.5 & 25.9 \\
\hline
\end{tabular}

${ }^{\mathrm{a}} \mathrm{FY} 18 / 19$ : financial years 2018-2019.

${ }^{b}$ FY19/20: financial years 2019-2020.

${ }^{\mathrm{c}} \mathrm{BGPaH}$ : Babylon GP at Hand practice.

${ }^{d}$ NWLCCCG: North West London Collaboration of Clinical Commissioning Groups.

${ }^{\mathrm{e}}$ Available for $97.8 \%$ (349/357) of practices.

${ }^{\mathrm{f}}$ With the 1st percentile representing the most deprived and the $100^{\text {th }}$ representing the least.

${ }^{\mathrm{g}} \mathrm{N} / \mathrm{A}$ : not available.

${ }^{\mathrm{h}}$ Absolute values were not published.

${ }^{\mathrm{i}}$ Employed status included "Full-time paid work (30 hours or more each week)"; "Part-time paid work (under 30 hours each week)"; and "Full-time education at school, college or university".

j'Other included "Permanently sick or disabled," "Fully retired from work," "Looking after the family or home," and "Doing something else".

\section{Weighting of Patient Population}

The average need index (the factor describing the size of the weighted population relative to the registered population) for
Babylon GP at Hand was between $27.5 \%$ and $43.9 \%$ lower for the core services and the core services adapted weighting methodologies, respectively (Table 3). Smaller differences were observed in the Carr-Hill method. 
Table 3. Average need indices for the 3 weighting methodologies for Babylon GP at Hand practice and the average of North West London Collaboration of Clinical Commissioning Groups for FY18/19 and FY19/20.

\begin{tabular}{llll}
\hline Weighting methodology & BGPaH $^{\mathrm{a}}$ need index & NWLCCCG ${ }^{\mathrm{b}}$ need index & Difference $^{\mathrm{c}}$, absolute $(\%)^{\circ}$ \\
\hline Core services & 0.66 & 0.93 & $0.26(28.4)$ \\
FY18/19 & 0.67 & 0.92 & $0.25(27.5)$ \\
FY19/20 & & & $0.39(43.7)$ \\
Core services adapted & 0.50 & 0.88 & $0.39(43.9)$ \\
FY18/19 & 0.49 & 0.88 & $-0.08(-8.2)$ \\
FY19/20 & & & $0.03(3.2)$ \\
Carr-Hill & 1.00 & 0.93 & 0.93 \\
FY18/19 & 0.90 & & \\
FY19/20 & &
\end{tabular}

${ }^{\mathrm{a}} \mathrm{BGPaH}$ : Babylon GP at Hand practice.

${ }^{b}$ NWLCCCG: North West London Collaboration of Clinical Commissioning Groups.

${ }^{\mathrm{c}}$ Numbers may not sum due to rounding.

${ }^{\mathrm{d}}$ FY18/19: financial years 2018-2019.

${ }^{\mathrm{e}}$ FY19/20: financial years 2019-2020.

\section{Cost Per Weighted Patient}

Before statistical analysis, the cost per weighted patient for Babylon GP at Hand was increased by $12 \%$ (Figure $2 \mathrm{E}$ ) to correct for lower than expected activity rates reported in an independent review of the practice [42].

The 1-sided, simple $z$ test was performed on a primary care network level, where the spending per weighted patient was normally distributed. A significantly lower cost per weighted patient for Babylon GP at Hand was observed for all weighting methodologies across both years. This was between $12.4 \%$ (£93) to $54.4 \%$ (£389) lower in FY18/19 and $15.2 \%$ (£114) to $50.9 \%$ (£362) lower in FY19/20 (Table 4).

Practice-level data were not normally distributed, there was a high number of outliers, and the Babylon GP at Hand practice was not of a comparable size; thus, the 1-sided, simple $z$ test was not performed. The Babylon GP at Hand practice's percentile among the other 357 practices is shown Table 5.

Table 4. Summary of cost per weighted patient for Babylon GP at Hand compared with the North West London Collaboration of Clinical Commissioning Groups average, including absolute and percentage differences and 1-sided, simple $z$ test results for FY18/19 and FY19/20.

\begin{tabular}{|c|c|c|c|c|}
\hline Weighting methodology & $\begin{array}{l}\mathrm{BGPaH}^{\mathrm{a}} \text { cost }(\mathfrak{£}) \text { per } \\
\text { weighted patient, } £\end{array}$ & $\begin{array}{l}\text { NWLCCCG }^{\mathrm{b}} \text { cost }(£) \text { per } \\
\text { weighted patient, } £\end{array}$ & $\begin{array}{l}\text { Difference in } \operatorname{cost}^{\mathrm{c}}(\mathfrak{f}), \\
\text { amount }(\%)\end{array}$ & $P$ value \\
\hline \multicolumn{5}{|l|}{ Core services } \\
\hline FY18/19 de & 492 & 715 & $-223(-31.2)$ & $<.001$ \\
\hline FY19/20 ${ }^{\mathrm{f}}$ & 468 & 714 & $-246(-34.5)$ & $<.001$ \\
\hline \multicolumn{5}{|l|}{ Core services adapted } \\
\hline $\mathrm{FY} 18 / 19^{\mathrm{e}}$ & 656 & 748 & $-93(-12.4)$ & .047 \\
\hline FY19/20 & 635 & 749 & $-114(-15.2)$ & .006 \\
\hline \multicolumn{5}{|l|}{ Carr-Hill } \\
\hline $\mathrm{FY} 18 / 19^{\mathrm{e}}$ & 325 & 714 & $-389(-54.4)$ & $<.001$ \\
\hline FY19/20 & 349 & 711 & $-362(-50.9)$ & $<.001$ \\
\hline
\end{tabular}

${ }^{\mathrm{a}}$ BGPaH: Babylon GP at Hand.

${ }^{\mathrm{b}}$ NWLCCCG: North West London Collaboration of Clinical Commissioning Group average, excluding Babylon GP at Hand.

${ }^{\mathrm{c}}$ Numbers may not sum due to rounding.

${ }^{\mathrm{d}}$ FY18/19: financial years 2018-2019.

e Adjusted for inflation to be comparable to FY19/20 costs.

${ }^{f}$ FY19/20: financial years 2019-2020. 
Table 5. Percentile rank of Babylon GP at Hand practice among all practices in North West Central London Collaboration of Clinical Commissioning Groups.

\begin{tabular}{ll}
\hline Weighting methodology & Babylon GP at Hand, percentile $^{\mathrm{a}}$ \\
\hline Core services & 3rd \\
FY18/19 & $3 \mathrm{rd}$ \\
FY19/20 & \\
Core services adapted & 15 th \\
FY18/19 & 9 th \\
FY19/20 & \\
Carr-Hill & 2nd \\
FY18/19 & 2nd \\
FY19/20 & \\
\hline
\end{tabular}

${ }^{\mathrm{a}}$ With the $1^{\text {st }}$ percentile representing the lowest spending per weighted patient and the $100^{\text {th }}$ representing the highest.

${ }^{b}$ FY18/19: financial years 2018-2019.

${ }^{c}$ FY19/20: financial years 2019-2020.

A summary of the total acute spending, registered populations, need indices, weighted populations, and cost per weighted patient for each practice and primary care network can be found in Multimedia Appendix 2.

\section{Discussion}

\section{Principal Results}

This paper is the first to show that an association between a highly accessible, 24/7, digital-first model of primary care and significantly lower acute hospital costs. This was observed over 2 consecutive years and across all 3 methodologies used to adjust for health care need. The spending per weighted patient for Babylon GP at Hand practice was $12 \%, 31 \%$, and $54 \%$ ( $£ 93$, $P=.047$; $223, P<.001$; and $£ 389, P<.001)$ lower than the regional average in FY18/19 for the core services adapted, core services, and Carr-Hill weighting methodologies, respectively. In FY19/20, it was $15 \%, 35 \%$, and $51 \%(£ 114, P=.006$; $£ 246$, $P<.001$; and £362, $P<.001)$ lower. This represented a lower total spending for the Babylon GP at Hand population in FY18/19 of $£ 1.37$ million, $£ 4.40$ million, and $£ 11.6$ million for the core services adapted, core services, and Carr-Hill weighting methodologies, respectively. In FY19/20, the equivalent figures were $£ 3.26$ million, $£ 9.54$ million, and $£ 18.8$ million, respectively.

The reduction in hospital care costs observed is likely to be much greater than the additional cost of delivering 24/7, digital-first primary care. In FY19/20, the Babylon GP at Hand practice delivered $23 \%$ more appointments per Carr-Hill weighted patient than the national average [35]. Even if primary care costs grew linearly with the number of appointments, this would translate to additional costs of $£ 36$ (based on an average funding per patient of $£ 155$ in FY19/20 [48] and assuming that primary care funding equals the costs of provision). Even after these additional costs were accounted for, the savings in FY19/20 would still be between $£ 78$ and $£ 326$ per weighted patient. Furthermore, any additional digital-first primary care costs are borne by the provider (Babylon GP at Hand) and not by the NHS, as NHS primary care practice payments are capitated rather than activity based. The full acute cost savings therefore accrue to the NHS.

\section{Limitations}

First, the main limitation is that patient-level data were not available; therefore, it was not possible to examine the causal factors behind the lower costs observed for patients receiving $24 / 7$, digital-first, primary care. Second, given that patients chose which practice to join, there might have been a degree of self-selection that was not corrected for by the weighting formulae used. However, adjustments, such as prior use of health care services by Babylon GP at Hand members, were made for known differences. This was conservative and acted to increase the cost per weighted person for the Babylon GP at Hand practice, suggesting that the cost savings may be greater than those shown. Further work is needed to access patient-level data, which could explain in which areas savings are made, eliminate self-selection bias, and reduce the need for adjustments.

The wider applicability of the findings is limited in part by the registered population of Babylon GP at Hand and by the spending categories returned in the FOI request. The population of Babylon GP at Hand is concentrated in working age adults, 95.9\% $(58,113 / 60,587)$ of patients in FY19/20 were between 20 to 59 years old compared to $62.6 \%(1,551,717 / 2,478,709)$ in the rest of the region. This could partially explain the higher percentage of employment observed in the Babylon GP at Hand population. The weighting formulae adjusted for the population differences, as evidenced by the Core Service Adapted need index in FY19/20 being 43.9\% lower for Babylon GP at Hand than the regional average. However, interpretation of the findings is limited for other age ranges. The spending data returned in the FOI request did not include mental health, community, or primary care prescription spending, which represented $36 \%$ of the total budget for the Clinical Commissioning Group core services in FY19/20 [36]. Resultantly, the effect of $24 / 7$ digital-first health care on this 
portion of spending has not been determined. However, there are reasons to believe that the same effect would be observed in these categories, as has been shown elsewhere [49].

This study is focused on acute hospital spending but did not assess the quality and therefore health care value. Assessing the quality of primary care is difficult given its broadness and the lack of robust quality metrics. However, during the period of investigation, Babylon GP at Hand practice was rated "Good" by the Care Quality Commission; scored $92 \%$ and $96 \%$ in all available Quality Outcome Framework points in FY18/19 and FY19/20 [50], respectively; and 94.4\% (146,077/154,738) of patient ratings for clinical consultations were 4 or 5 stars out of 5 during the study period (SG Winward, MD, unpublished data, April 1, 2018, to March 31, 2020).

The Carr-Hill weighting methodology factors in demographics and other drivers of need, but its purpose is to determine primary care funding rather than acute care spending. This weighting approach was recommended in the FOI response and hence it was included but is not considered as robust as the core services adapted and core services methodologies. Therefore, the central finding of this paper is a $15 \%-35 \%$ lower spending per weighted patient for members of Babylon GP at Hand in FY19/20.

The accuracy of the analysis in this paper is contingent on the quality and reliability of the NHS data that were provided in the FOI request (Multimedia Appendix 1).

\section{Comparison With Prior Work}

To our knowledge, this study is the first to assess the impact that a highly accessible, digital-first model of primary care has on acute hospital spending. Although the findings cannot infer causality, they are consistent with those of other publications. These include, for example, a link between accessible primary care and reduced demand for other services [32]; and an NHS England commissioned report on Babylon GP at Hand, which found patients were significantly less likely to attend ED and outpatient appointments than was a control population [42]. The authors of the report have since called for more evidence to be obtained on the sustainability of such services, as this paper seeks to provide [51].

The paper is aligned with the majority of the literature in showing that digital health solutions can reduce costs [23-25,27]. It adds insight in two areas where research is sparse. First, it is an assessment of a digital-first model of care for a wide range of conditions as opposed to a digital tool in a single condition; second, it quantifies cost savings from the perspective of the health system [19]. The results are particularly important in the context of the national direction of travel laid out in the NHS Long Term Plan, which states that all patients must be able to access digital-first primary care by the end of the 2024 financial year [31].

Several areas requiring further research have been identified. To increase confidence in the conclusions, assessment of patient-level data over all spending categories (ie, mental health, prescriptions, and community and acute hospital spending) during the same period is required. Further research is also needed to fully assess the impact of the model of care on quality outcomes. The effectiveness of telehealth solutions has been shown to be linked to the provider [27], so further work with alternate providers is required to establish if the observed benefits are uniform.

\section{Conclusions}

This paper has demonstrated that highly accessible, 24/7, digital-first primary care was associated with lower acute hospital spending for a health system. This effect was sustained over a 2-year period, during which the population under investigation doubled in size, demonstrating that the effect is scalable. Further work using patient-level data is needed to be able to generalize these findings to a wider demographic of patients and to understand the efficacy of digital-first primary care across different populations of patients.

\section{Authors' Contributions}

SW contributed to the conceptualization, methodology, formal analysis, and writing of the original draft. TP contributed to the writing and review of the manuscript. MAS contributed to the writing, review, and editing of the manuscript. MN provided supervision and contributed to the writing and review of the manuscript.

\section{Conflicts of Interest}

All the authors are employees of, and have share options in, Babylon Health.

\section{Multimedia Appendix 1}

Freedom of Information (FOI) request and response.

[XLSX File (Microsoft Excel File), 20 KB-Multimedia Appendix 1]

\section{Multimedia Appendix 2}

Summary of results.

[XLSX File (Microsoft Excel File), 155 KB-Multimedia Appendix 2]

\section{References}

1. Current health expenditure as percentage of gross domestic product - data by WHO region. World Health Organization. URL: https://apps.who.int/gho/data/view.main.GHEDCHEGDPSHA2011REGv?lang=en [accessed 2020-11-13] 
2. United Nations: Department of Economic and Social Affairs. World Population Ageing 2019. 2020. URL: https://www. un.org/development/desa/pd/sites/www.un.org.development.desa.pd/files/files/documents/2020/Jan/ un 2019 worldpopulationageing report.pdf [accessed 2020-11-13]

3. Nghiem SH, Connelly LB. Convergence and determinants of health expenditures in OECD countries. Health Econ Rev 2017 Aug 17;7(1):29 [FREE Full text] [doi: 10.1186/s13561-017-0164-4] [Medline: 28819772]

4. Ricciardi W, Pita Barros P, Bourek A, Brouwer W, Kelsey T, Lehtonen L, Expert Panel on Effective Ways of Investing in Health (EXPH). How to govern the digital transformation of health services. Eur J Public Health 2019 Oct 01;29(Supplement_3):7-12 [FREE Full text] [doi: 10.1093/eurpub/ckz165] [Medline: 31738442]

5. World Health Organization. Monitoring and Evaluating Digital Health Interventions: A Practical Guide to Conducting Research and Assessment. Geneva: World Health Organization; 2016.

6. Bashshur RL, Shannon G, Krupinski EA, Grigsby J. Sustaining and realizing the promise of telemedicine. Telemed J E Health 2013 May;19(5):339-345 [FREE Full text] [doi: 10.1089/tmj.2012.0282] [Medline: 23289907]

7. Expert Panel on effective ways of investing in Health. Assessing the impact of digital transformation of health services. European Commission. 2019 Jan. URL: https://ec.europa.eu/health/sites/health/files/expert panel/docs/ 022 digitaltransformation en.pdf [accessed 2020-11-13]

8. Baird B. How has general practice responded to the Covid-19 (coronavirus) outbreak?: Kings Fund URL: https://www. kingsfund.org.uk/blog/2020/04/covid-19-general-practice [accessed 2020-11-13]

9. Fagherazzi G, Goetzinger C, Rashid MA, Aguayo GA, Huiart L. Digital health strategies to fight COVID-19 worldwide: challenges, recommendations, and a call for papers. J Med Internet Res 2020 Jun 16;22(6):e19284 [FREE Full text] [doi: 10.2196/19284] [Medline: 32501804 ]

10. Keesara S, Jonas A, Schulman K. Covid-19 and health care's digital revolution. N Engl J Med 2020 Apr 02:382. [doi: 10.1056/NEJMp2005835] [Medline: 32240581]

11. Golinelli D, Boetto E, Carullo G, Nuzzolese AG, Landini MP, Fantini MP. Adoption of digital technologies in health care during the COVID-19 pandemic: systematic review of early scientific literature. J Med Internet Res 2020 Nov 06;22(11):e22280 [FREE Full text] [doi: 10.2196/22280] [Medline: 33079693]

12. Telehealth. World Health Organization. URL: http://www.who.int/gho/goe/telehealth/en/ [accessed 2020-11-13]

13. Powell RE, Stone D, Hollander JE. Patient and health system experience with implementation of an enterprise-wide telehealth scheduled video visit program: mixed-methods study. JMIR Med Inform 2018 Feb 13;6(1):e10 [FREE Full text] [doi: 10.2196/medinform.8479] [Medline: 29439947]

14. Fatehi F, Martin-Khan M, Smith AC, Russell AW, Gray LC. Patient satisfaction with video teleconsultation in a virtual diabetes outreach clinic. Diabetes Technol Ther 2015 Jan;17(1):43-48. [doi: 10.1089/dia.2014.0159] [Medline: 25296189]

15. Powell RE, Henstenburg JM, Cooper G, Hollander JE, Rising KL. Patient perceptions of telehealth primary care video visits. Ann Fam Med 2017 Dec;15(3):225-229 [FREE Full text] [doi: 10.1370/afm.2095] [Medline: 28483887]

16. Greenhalgh T, Shaw S, Wherton J, Vijayaraghavan S, Morris J, Bhattacharya S, et al. Real-world implementation of video outpatient consultations at macro, meso, and micro levels: mixed-method study. J Med Internet Res 2018 Dec 17;20(4):e150 [FREE Full text] [doi: 10.2196/jmir.9897] [Medline: 29625956]

17. Backhaus A, Agha Z, Maglione ML, Repp A, Ross B, Zuest D, et al. Videoconferencing psychotherapy: a systematic review. Psychol Serv 2012 May;9(2):111-131. [doi: 10.1037/a0027924] [Medline: 22662727]

18. Donaghy E, Atherton H, Hammersley V, McNeilly H, Bikker A, Robbins L, et al. Acceptability, benefits, and challenges of video consulting: a qualitative study in primary care. Br J Gen Pract 2019 Sep;69(686):e586-e594 [FREE Full text] [doi: 10.3399/bjgp19X704141] [Medline: $\underline{31160368]}$

19. Snoswell CL, Taylor ML, Comans TA, Smith AC, Gray LC, Caffery LJ. Determining if telehealth can reduce health system costs: scoping review. J Med Internet Res 2020 Oct 19;22(10):e17298. [doi: 10.2196/17298]

20. Paré G, Moqadem K, Pineau G, St-Hilaire C. Clinical effects of home telemonitoring in the context of diabetes, asthma, heart failure and hypertension: a systematic review. J Med Internet Res 2010 Jun 16;12(2):e21 [FREE Full text] [doi: 10.2196/jmir.1357] [Medline: 20554500]

21. Paré G, Jaana M, Sicotte C. Systematic review of home telemonitoring for chronic diseases: the evidence base. J Am Med Inform Assoc 2007;14(3):269-277 [FREE Full text] [doi: 10.1197/jamia.M2270] [Medline: 17329725]

22. McLean S, Nurmatov U, Liu JL, Pagliari C, Car J, Sheikh A. Telehealthcare for chronic obstructive pulmonary disease. Cochrane Database Syst Rev 2011 Jul 06(7):CD007718. [doi: 10.1002/14651858.CD007718.pub2] [Medline: 21735417]

23. Elbert NJ, van OH, van RW, Ekeland AG, Hakkaart-van RL, Raat H, et al. Effectiveness and cost-effectiveness of ehealth interventions in somatic diseases: a systematic review of systematic reviews and meta-analyses. J Med Internet Res 2014;16(4):e110 [FRE Full text] [doi: 10.2196/jmir.2790] [Medline: 24739471]

24. Polisena J, Coyle D, Coyle K, McGill S. Home telehealth for chronic disease management: a systematic review and an analysis of economic evaluations. Int J Technol Assess Health Care 2009 Jul;25(3):339-349. [doi:

10.1017/S0266462309990201] [Medline: 19619353]

25. de la Torre-Díez I, López-Coronado M, Vaca C, Aguado JS, de Castro C. Cost-utility and cost-effectiveness studies of telemedicine, electronic, and mobile health systems in the literature: a systematic review. Telemed J E Health 2015 Feb;21(2):81-85 [FRE Full text] [doi: 10.1089/tmj.2014.0053] [Medline: 25474190] 
26. Flodgren G, Rachas A, Farmer A, Inzitari M, Shepperd S. Interactive telemedicine: effects on professional practice and health care outcomes. Cochrane Database Syst Rev 2015 Sep 07(9):CD002098 [FREE Full text] [doi: 10.1002/14651858.CD002098.pub2] [Medline: 26343551]

27. Ekeland AG, Bowes A, Flottorp S. Effectiveness of telemedicine: a systematic review of reviews. Int J Med Inform 2010 Nov;79(11):736-771. [doi: 10.1016/j.ijmedinf.2010.08.006] [Medline: 20884286]

28. Rahimi K. Digital health and the elusive quest for cost savings. Lancet Digit Health 2019 Jul;1(3):e108-e109 [FREE Full text] [doi: 10.1016/S2589-7500(19)30056-1] [Medline: 33323258]

29. Sweet CC, Jasik CB, Diebold A, DuPuis A, Jendretzke B. Cost savings and reduced health care utilization associated with participation in a digital diabetes prevention program in an adult workforce population. J Health Econ Outcomes Res 2020;7(2):139-147 [FREE Full text] [doi: 10.36469/jheor.2020.14529] [Medline: 32884964]

30. Whaley CM, Bollyky JB, Lu W, Painter S, Schneider J, Zhao Z, et al. Reduced medical spending associated with increased use of a remote diabetes management program and lower mean blood glucose values. J Med Econ 2019 Sep;22(9):869-877. [doi: 10.1080/13696998.2019.1609483] [Medline: $\underline{\text { 31012392] }}$

31. NHS Long Term Plan. The National Health Service. 2019 Jan 07. URL: https://www.longtermplan.nhs.uk [accessed 2020-11-13]

32. Whittaker W, Anselmi L, Kristensen S, Lau Y, Bailey S, Bower P, et al. Associations between extending access to primary care and emergency department visits: a difference-in-differences analysis. PLoS Med 2016 Sep;13(9):e1002113 [FREE Full text] [doi: 10.1371/journal.pmed.1002113] [Medline: 27598248]

33. Patients registered at a GP practice. NHS Digital. URL: https://digital.nhs.uk/data-and-information/publications/statistical/ patients-registered-at-a-gp-practice [accessed 2020-11-13]

34. Standard General Medical Services Contract. NHS England and NHS Improvement. 2019. URL: https://www.england.nhs.uk/ wp-content/uploads/2019/11/gms-contract-october-2019.pdf [accessed 2020-11-13]

35. Appointments in general practice (2018-2020). NHS Digtial. URL: https://digital.nhs.uk/data-and-information/publications/ statistical/appointments-in-general-practice [accessed 2020-11-13]

36. Infographics: fair shares - a guide to NHS allocations. NHS England and NHS Improvement. 2020 Feb 10. URL: https:/ /www.england.nhs.uk/publication/infographics-fair-shares-a-guide-to-nhs-allocations/ [accessed 2020-11-13]

37. Technical guide to allocation formulae and pace of change for 2019/20 to 2023/24 revenue allocations. NHS England. 2019 May 30. URL: https://www.england.nhs.uk/publication/

technical-guide-to-allocation-formulae-and-pace-of-change-for-2019-20-to-2023-24-revenue-allocations/ [accessed 2020-11-13]

38. Dyson M. Global sum allocation formula. British Medical Association. URL: https://www.bma.org.uk/advice-and-support/ gp-practices/funding-and-contracts/global-sum-allocation-formula [accessed 2020-11-13]

39. NHS payments to general practice. NHS Digital. URL: https://digital.nhs.uk/data-and-information/publications/statistical/ nhs-payments-to-general-practice [accessed 2020-11-13]

40. Baird B. Primary care networks explained. Kings Fund. 2019. URL: https://www.kingsfund.org.uk/publications/ primary-care-networks-explained [accessed 2020-11-13]

41. Primary care networks. NHS England. URL: https://www.england.nhs.uk/primary-care/primary-care-networks/ [accessed 2020-11-13]

42. Evaluation of Babylon GP at Hand Final report. Ipsos MORI and York Health Economics Consortium. 2019 May. URL: https://www.hammersmithfulhamccg.nhs.uk/newspublications/publications-policies.aspx?n=9446 [accessed 2020-11-13]

43. Hospital admitted patient care activity. NHS Digital. URL: https://digital.nhs.uk/data-and-information/publications/statistical/ hospital-admitted-patient-care-activity [accessed 2020-11-13]

44. National cost collection for the NHS. NHS England. 2019. URL: https://www.england.nhs.uk/national-cost-collection/ [accessed 2020-11-13]

45. GDP deflators at market prices, and money GDP November 2020 (Spending Review). Office of National Statistics, GOVUK. URL: https://www.gov.uk/government/statistics/

gdp-deflators-at-market-prices-and-money-gdp-november-2020-spending-review [accessed 2020-11-13]

46. Jones E, Oliphant T, Peterson P. SciPy: open source scientific tools for Python. 2001. URL: http://www.scipy.org [accessed 2020-11-13]

47. Public health profiles. Public Health England. 2021. URL: https://fingertips.phe.org.uk [accessed 2020-11-13]

48. GP practices were paid an average of $£ 155$ per patient in 2019/20. Pulse Today. 2020. URL: https://www.pulsetoday.co.uk/ news/practice-personal-finance/gp-practices-were-paid-an-average-of-155-per-patient-in-2019-20/ [accessed 2020-11-13]

49. Bashshur RL, Shannon GW, Bashshur N, Yellowlees PM. The empirical evidence for telemedicine interventions in mental disorders. Telemed J E Health 2016 Feb;22(2):87-113 [FREE Full text] [doi: 10.1089/tmj.2015.0206] [Medline: 26624248]

50. Quality and outcomes framework. NHS Digital. URL: https://digital.nhs.uk/data-and-information/publications/statistical/ quality-and-outcomes-framework-achievement-prevalence-and-exceptions-data [accessed 2020-11-13]

51. Salisbury C, Quigley A, Hex N, Aznar C. Private video consultation services and the future of primary care. J Med Internet Res 2020 Oct 01;22(10):e19415 [FREE Full text] [doi: 10.2196/19415] [Medline: 32812887] 


\section{Abbreviations}

ED: emergency department

FOI: freedom of information

FY: financial year

GDP: gross domestic product

NHS: National Health Service (of the United Kingdom)

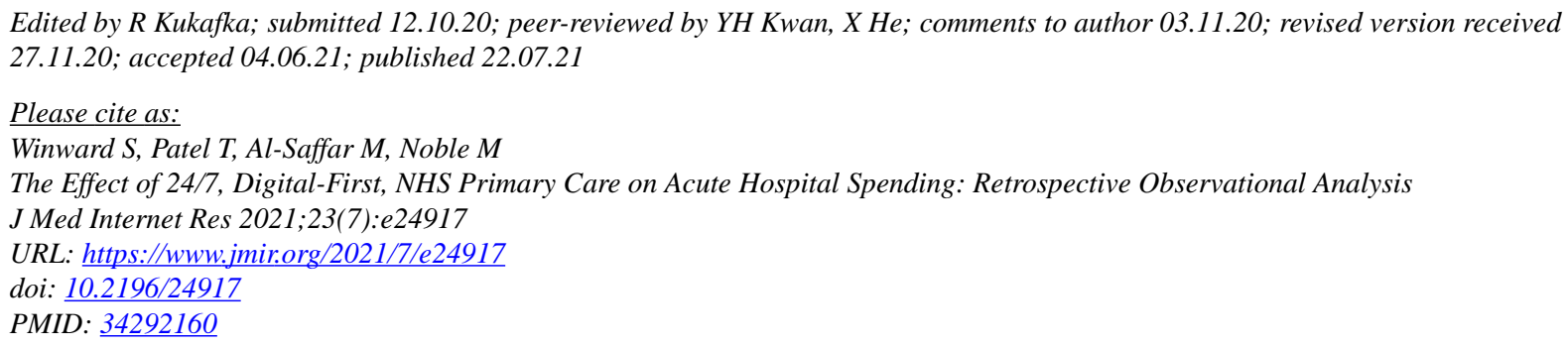

(C)Sam Winward, Tejal Patel, Mazin Al-Saffar, Matthew Noble. Originally published in the Journal of Medical Internet Research (https://www.jmir.org), 22.07.2021. This is an open-access article distributed under the terms of the Creative Commons Attribution License (https://creativecommons.org/licenses/by/4.0/), which permits unrestricted use, distribution, and reproduction in any medium, provided the original work, first published in the Journal of Medical Internet Research, is properly cited. The complete bibliographic information, a link to the original publication on https://www.jmir.org/, as well as this copyright and license information must be included. 